\title{
Nucleation and Growth Mechanism of Si Amorphous Film Deposited by PIAD
}

\author{
D. Li, ${ }^{1,2}$ G. L. Liu, ${ }^{1}$ Y. Yang, ${ }^{1}$ J. H. Wu, ${ }^{3}$ and Z. R. Huang ${ }^{1}$ \\ ${ }^{1}$ State Key Laboratory of High Performance Ceramics and Superfine Microstructure, Shanghai Institute of Ceramics, \\ Chinese Academy of Sciences, 1295 Dingxi Road, Shanghai 200050, China \\ ${ }^{2}$ Graduate University of Chinese Academy of Sciences, Beijing 100049, China \\ ${ }^{3}$ Energy Materials Research Center, Shanghai Institute of Ceramics, Chinese Academy of Sciences, 1295 Dingxi Road, \\ Shanghai 200050, China \\ Correspondence should be addressed to Y. Yang; yangyong@mail.sic.ac.cn
}

Received 3 October 2012; Revised 28 December 2012; Accepted 4 January 2013

Academic Editor: Masayuki Nogami

Copyright (C) 2013 D. Li et al. This is an open access article distributed under the Creative Commons Attribution License, which permits unrestricted use, distribution, and reproduction in any medium, provided the original work is properly cited.

\begin{abstract}
The nanoscale Si films with the thickness of $2 \mathrm{~nm}, 5 \mathrm{~nm}, 10 \mathrm{~nm}$, and $20 \mathrm{~nm}$ were deposited by plasma ion assisted deposition (PIAD) on glass substrate, in order to investigate the initial stage and the nucleation and growth mechanism of the Si film. The atomic force microscopy (AFM) was used to investigate the surface topography of the as-deposited Si film. The initial nucleation and growth process of the film was described. The continuous film had been already formed when the film thickness was $10 \mathrm{~nm}$. The growth of the deposited Si film accorded with the Volmer-Weber growth mode.
\end{abstract}

\section{Introduction}

The use of surface coating for surface modification of ceramics is an important alternative as a means of extending the performance of ceramic materials in a wide range of applications [1]. The amorphous silicon (a-Si) film was deposited as surface-modification film on the $\mathrm{SiC}$ ceramic matrix which was applied in advanced optical systems, in order to modify the microstructure defects or pores on the substrate surface and provide an alternative surface which would make the polishing process more easily $[2,3]$. Besides, the a-Si film was the precursor of the crystalline Si film which was widely used in photovoltaic industry and extensive investigations on the technique and mechanism of the crystallization were carried out $[4,5]$.

The a-Si has been reported to be deposited by typical physical vapor deposition (PVD), hot-wire chemical vapor deposition (HWCVD) [6], plasma-enhanced chemical vapor deposition (PECVD) [4], magnetron sputtering deposition [7], ultrahigh vacuum ion beam sputtering (UHV IBS) [8], and so on.
The PVD process which is an environmental friendly technology could prepare a compact and uniform a-Si film [9]. The PVD techniques including thermal evaporation techniques, sputtering technique, and ion assisted deposition have been used to fabricate $\mathrm{Si}$ modification films. In the typical process of the vacuum evaporation, the migration rate of atom on the surface of substrate is confined by the low incident energy (only the kinetic energy of thermal motion, $\sim 1 \mathrm{eV}$ ), and the preferred orientation growth and shadow effect could also result in the loose structure with columnar growth and holes in the final as-deposited film [10]. To solve this problem, the thermal evaporation techniques are combined with ion sources which provide additional energy and momentum to influence the properties of the asdeposited films, known as ion assisted deposition (IAD) [1113]. To reinforce the chemical reaction between the substrate and the as-deposited materials atoms which would finally improve the compactness and the adhesive strength of the deposited film, the plasma ion assisted deposition (PIAD), as one of the ion plating method, was introduced into the deposition process. The plasma produced by the advance 
plasma sources (APS) was distributed in the whole cavity, which would interact with the as-deposited material atoms to transfer high energy and to ionize the as-deposited atoms. The technological merits of this plasma source are recognized by the production of high performance coatings [14].

The microstructures of the a-Si film prepared by PIAD have been investigated and the excellent properties were proved for various applications $[1,9]$. But little attention was paid to the initial stage and the growth mechanism of the a-Si film deposited by PIAD, which would be important to the microstructure and the final surface morphology of the amorphous film.

One of the reasons to this neglect is that most of the surface-sensitive analytical techniques applied in coating study could not be available for nanoscale observation. The nuclei with the size larger than $50 \mathrm{~nm}$ could be successfully observed by high-resolution SEM $[15,16]$. The topography of the nuclei with the size of several nanometers could be clearly observed by the atomic force microscopy (AFM) [17]. So, only the atomic force microscopy (AFM) has been widely used to study the growth mechanisms and dynamics and the nanometer scale morphology of crystal surfaces, since its invention in 1986 [18].

In this work, a detailed study of the nucleation and growth mechanism of the PIAD a-Si film on silicate glass substrate has been performed. The Si films with different thickness of $2 \mathrm{~nm}, 5 \mathrm{~nm}, 10 \mathrm{~nm}$, and $20 \mathrm{~nm}$ were prepared. The nucleation and growth process of the film was observed by AFM technique. The mean size and height of the nucleus (island) was estimated by line scan in the AFM images. The nucleation and growth phenomenon had been described and analyzed. The continuous film had been already formed when the film thickness was $10 \mathrm{~nm}$, and the growth process of Si film deposited on glass substrate by PIAD was found to accord with Volmer-Weber growth mode. The deposited Si clusters with the size of $1-2 \mathrm{~nm}$, as the deposition unit, were always present on the surface of as-deposited continuous Si film in the PAID process.

\section{Experimental Details}

The nanosilicon film was deposited on silicate glass in a box-type vacuum coating machine (Leybold APS 1104 coater, Germany) with plasma ion source assisted. The target was a high-purity polycrystalline Si source (99.999\%, Special Alloy Powder Metallurgy Materials, General Research Institute for Nonferrous Metals (GRINM)). Before the deposition, the substrates were cleaned successively with water in an ultrasonic cleaner and then rinsed by acetone. All samples were performed at $200^{\circ} \mathrm{C}$. The vacuum in the chamber before deposition was $2.0 \times 10^{-3} \mathrm{~Pa}$. The deposition rate remained $0.1 \mathrm{~nm} / \mathrm{s}$ and the power of ion source was $6 \mathrm{~kW}$ during the deposition process. The mean thickness of Si film was designed to be $2 \mathrm{~nm}, 5 \mathrm{~nm}, 10 \mathrm{~nm}$, and $20 \mathrm{~nm}$, which was realtime monitored by a quartz crystal oscillator.

The surface topographic signatures of the substrate and the Si films were observed in detail by the atomic force microscope (AFM) (SPI3800N and 144 SPA300HV, SEIKO II, NSK Ltd., Japan) in ambient atmosphere at room temperature in contact mode. The average height (thickness) and the size of the crystalline grain in full width at half maximum (FWHM) were estimated by the line scan in the AFM images and the surface roughness reported as peak value (PV) and root mean square roughness (RMS) was also calculated.

\section{Results}

3.1. The Surface Morphology of the Substrate. It is known that the properties of the substrate surface would significantly affect not only the microstructure but also the growth mechanism especially at the initial stage of the film deposition. The defect or impurity sites on the substrate surface would be the priority areas of nucleation. To investigate the growth process of the nanoscale film, the required properties of the substrate surface was even crucial.

The typical AFM images of glass substrate surface in twodimensional (2D) and three-dimensional (3D) and the line scan profile on the image were shown in Figure 1. The surface was flat without defects or scratch. The RMS of substrate surface was $0.9 \mathrm{~nm}$ measured by AFM at a scan size of $400 \mu \mathrm{m}^{2}$. The line scan in the image showed that the surface fluctuation was gentle and the PV was about $1 \mathrm{~nm}$, which means the deposition films which were designed with more than $2 \mathrm{~nm}$ thick in this work would be obviously observed on this substrate.

3.2. The Surface Morphology of the Si Film. Si films with the thickness of $2 \mathrm{~nm}, 5 \mathrm{~nm}$, and $10 \mathrm{~nm}$ were deposited on glass substrate and the AFM topographic images of the surfaces were shown in Figure 2. Figures 2(a), 2(c), and 2(e) were the $2 \mathrm{D}$ surface topography of the $2 \mathrm{~nm}, 5 \mathrm{~nm}$, and $10 \mathrm{~nm} \mathrm{Si}$ film, respectively, and Figures 2(b), 2(d), and 2(f) were the 3D images of the selected area in the corresponding $2 \mathrm{D}$ images.

The light spheroids randomly dispersed on the surface of the $2 \mathrm{~nm}$ Si film in Figure 2(a) which could associate with the spheroids observed in Figure 2(b). This surface topography signature which was quite different from the surface of substrate could be induced by the deposition process. And the spheroids/protuberances could be the nucleus of $\mathrm{Si}$ crystallization at the initial stage of the film forming. In Figures 2(c) and 2(d) which showed the topography of the $5 \mathrm{~nm} \mathrm{Si} \mathrm{film,} \mathrm{the} \mathrm{density} \mathrm{and} \mathrm{the} \mathrm{size} \mathrm{of} \mathrm{the} \mathrm{dispersed}$ nanocrystallites, which have been confirmed in the $2 \mathrm{~nm}$ film, were obviously increased. As the thickness of the Si film increased to $10 \mathrm{~nm}$, the surface topography became smooth without nanocrystallites structure which has been seen in the $2 \mathrm{~nm}$ or $5 \mathrm{~nm}$ film; besides more and smaller spheroids were dispersed in Figure 2(f).

3.3. The Line Scan Profile of the Nuclei. The line scan profiles of the Si film with different thickness were shown in Figure 3, and the mean height and full width at half maximum (FWHM) of the spheroids on the surface of the Si film with different thickness were summarized in Table 1.

The height and the FWHM of the protuberances on the $2 \mathrm{~nm}$ Si surface were $1.4 \mathrm{~nm}$ and $100 \mathrm{~nm}$, respectively. When the thickness of the deposited film increased to $5 \mathrm{~nm}$, the height and FWHM of the nuclei increased to $3.7 \mathrm{~nm}$ and 

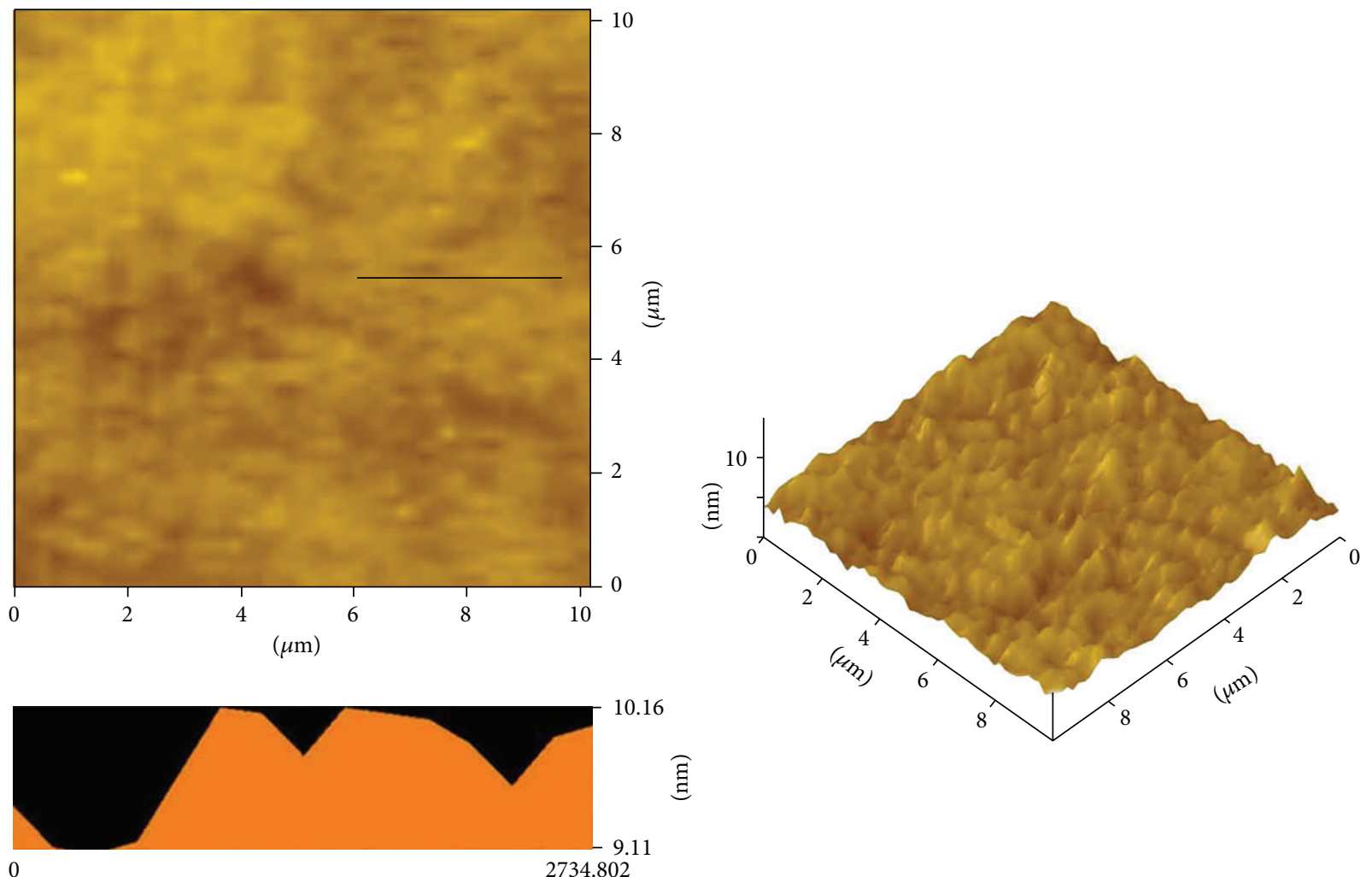

吾

$(\mathrm{nm})$

FIGURE 1: The AFM topographic image and line scan profile of glass substrate surface.

TABLE 1: The height and the FWHM of the nuclei on the surface of the Si film with different thickness.

\begin{tabular}{lccc}
\hline Thickness & $2 \mathrm{~nm}$ & $5 \mathrm{~nm}$ & $10 \mathrm{~nm}$ \\
Height & 1.4 & $3.7 \mathrm{~nm}$ & 0.9 \\
FWHM & $106.05 \mathrm{~nm}$ & $164.05 \mathrm{~nm}$ & $75.77 \mathrm{~nm}$ \\
\hline
\end{tabular}

$164 \mathrm{~nm}$, respectively. The Si nuclei with the intermediate state of merging were pointed out by arrows in Figure 3(c), which means that the coalescence process of the nuclei was progressively undergoing with the growth of the nuclei. The line scan profile of the film surface exhibited that the height and FWHM of the nuclei decreased to $0.9 \mathrm{~nm}$ and $75.8 \mathrm{~nm}$ instead of increasing with the film thickness, which indicated the growth stage/module of the deposited film was totally changed. The statistic results which have great dispersion indicated the grains in each early growth stage were presented on the film surface.

3.4. The Surface Roughness of Si Film. The surface roughness (PV and RMS) of the Si film with different thickness was measured at a scan size of $10 \mu \mathrm{m} \times 10 \mu \mathrm{m}$ which was shown in Table 2. The surface roughness increased when the Si film deposited on the substrate and with the thickness increase of the Si film from $2 \mathrm{~nm}$ to $5 \mathrm{~nm}$, which was consistent with the results of the line scan profiles on the Si film surface. The surface roughness of the Si film with $10 \mathrm{~nm}$ thick was
$10.2 \mathrm{~nm}(\mathrm{PV})$ and $0.8 \mathrm{~nm}$ (RMS) which would be comparable to the surface roughness of the substrate. The fundamental changes of the film surface roughness indicated there is no deep canyon across the whole film thickness between the independently grown-up islands. So the continues deposited film was expected.

\section{Discussion}

The emphases of this work were focused on the topographic signature of the Si nucleate on the substrate, the growth process, and mechanism of the nanoscale film. The whole process of the Si film growth on substrate would be described as the schematic diagram shown in Figure 4, by studying the AFM images of all the growth stages of the deposited film. The surface topography and the line scan profile of the $2 \mathrm{~nm}$ Si film indicated that the spheroid nuclei have been formed (Figures 2(a) and 3(a)). The nucleus shape was determined by the noninfiltration phenomenon between the substrate and the film component, which means the deposited Si atoms were more strongly bound to each other than they were bound to the substrate. This nucleation process was described as the first stage in Figure 4. The height and FWHM of the nuclei increased when the deposition thickness increased to $5 \mathrm{~nm}$, which indicated the nuclei were at the growth stage. The nuclei grew up independently or by nuclei coalescence which was proved by the line scan profile in Figure 3(b) and depicted as second stage in Figure 4. The nuclei continued to grow and 


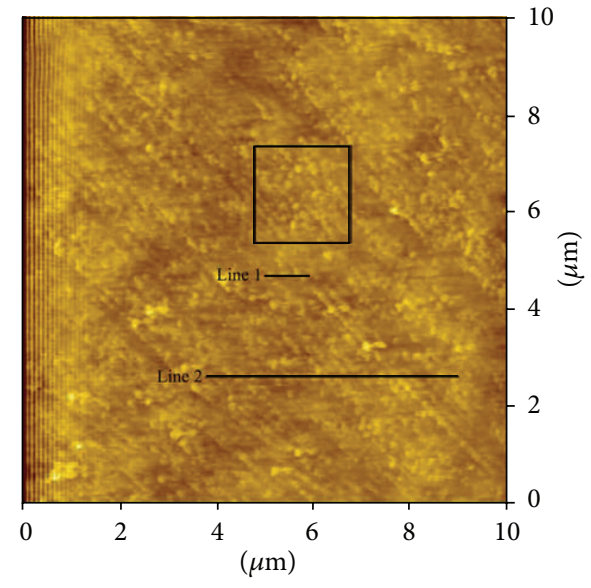

(a)

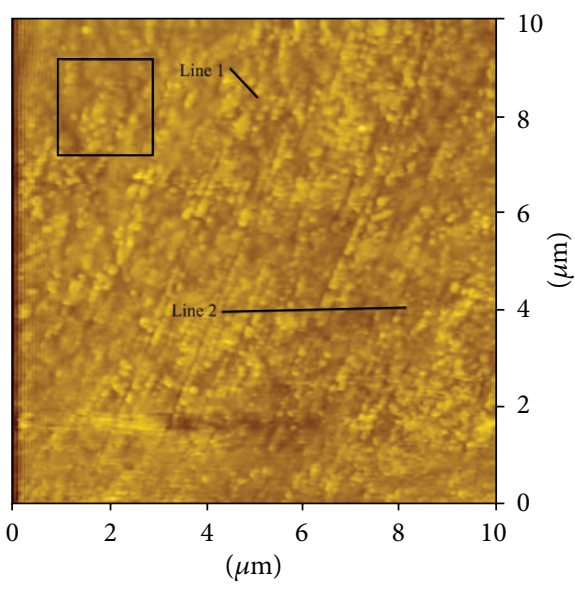

(c)

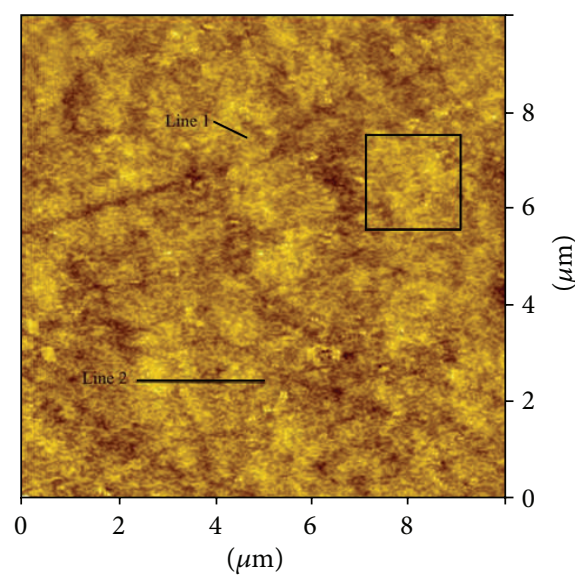

(e)

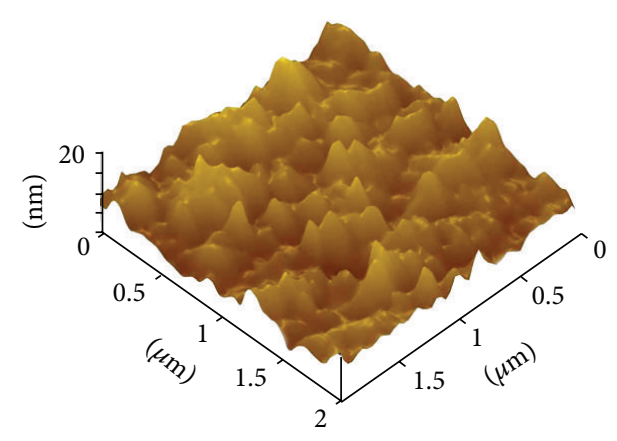

(d)

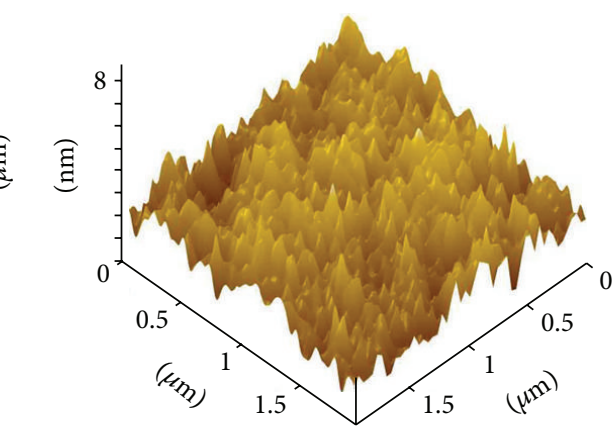

(f)

FIGURE 2: The surface topography images of the Si film with different thickness. The (a), (c), and (e) were the $10 \mu \mathrm{m} \times 10 \mu \mathrm{m} 2 \mathrm{D}$ images of $2 \mathrm{~nm}$, $5 \mathrm{~nm}$, and $10 \mathrm{~nm}$ Si film respectively, and the (b), (d), and (f) were the 3D images of the selected area in the 2D images of the corresponding Si films. 


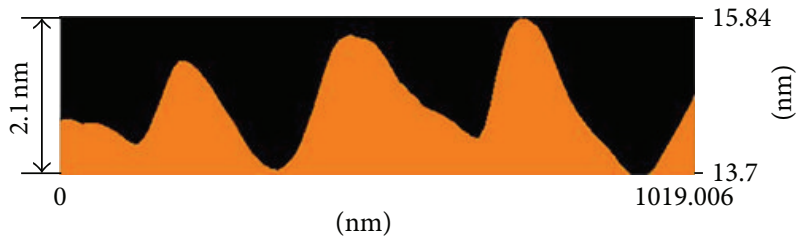

(a)

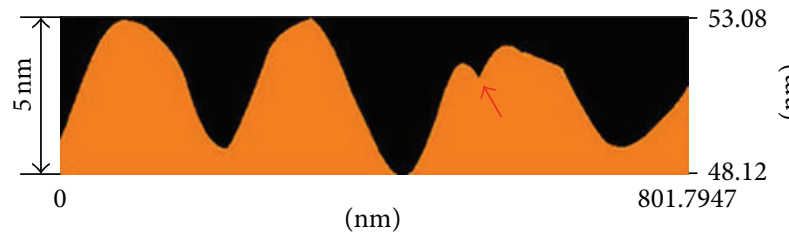

(c)

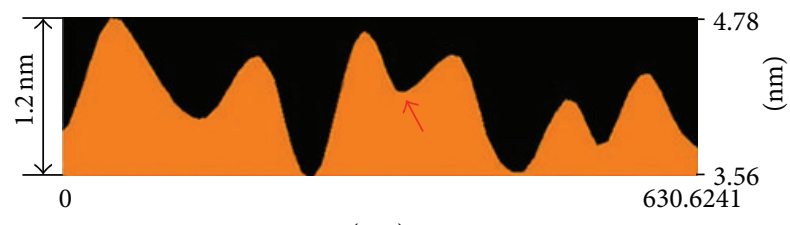

(nm)

(e)

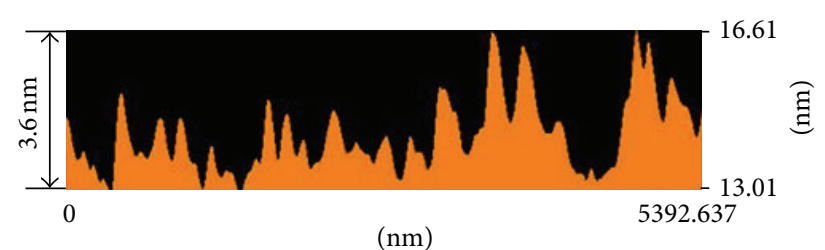

(b)

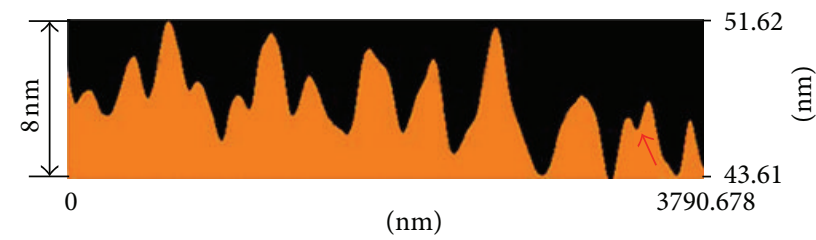

(d)

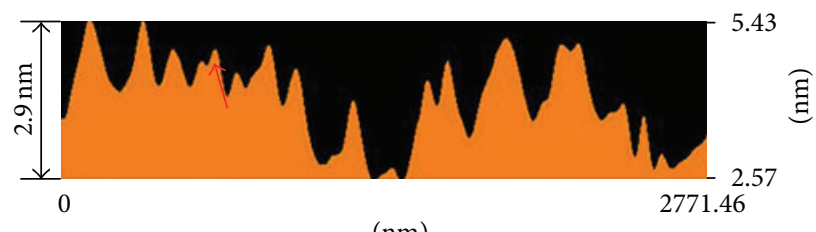

(nm)

(f)

FIgURE 3: The line scan profiles of the Si film with different thickness. The (a) and (b) were the profiles of the line scan marked in Figure 2(a), the (c) and (d) were the profiles of the line scan marked in Figure 2(c), and the (e) and (f) were the profiles of the line scan marked in Figure 2(e).
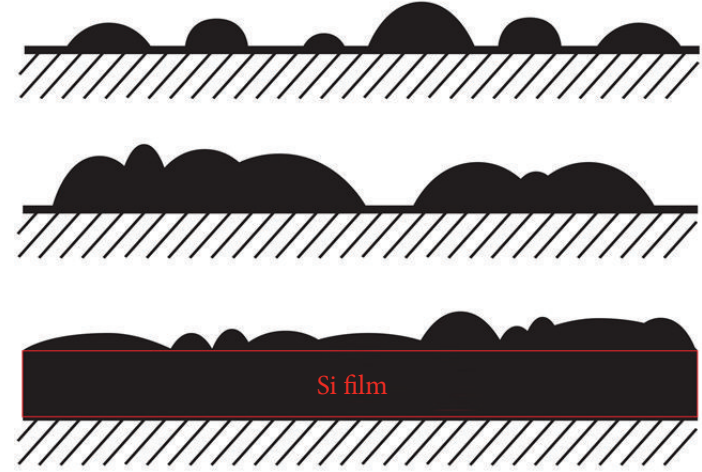

FIGURE 4: The schematic diagram of the deposition process of Si film on glass substrate.

coalesce until a continuous film formed which was depicted as the third stage in Figure 4. Those growth processes were accorded with the typical processes of Volmer-Weber growth mode $[19,20]$.

When the film thickness reached $10 \mathrm{~nm}$, the surface topography was totally changed without obviously crystallize nuclei but smooth surface was observed, and the surface roughness was also reduced to be comparable with the initial substrate surface. To figure out whether the $10 \mathrm{~nm}$ Si film was completely continuous or not, the surface of the $20 \mathrm{~nm} \mathrm{Si} \mathrm{film}$ was also observed by AFM. The surface topography image and line scan profile were shown in Figure 5. The surface of the $20 \mathrm{~nm}$ film showed the same feature with the $10 \mathrm{~nm}$ film,
TABLE 2: The surface roughness of the substrate and deposited Si films with different thickness.

\begin{tabular}{lcc}
\hline & PV $(\mathrm{nm})$ & RMS $(\mathrm{nm})$ \\
\hline Substrate & 10.1 & 0.8 \\
$2 \mathrm{~nm}$ Si film & 17.3 & 1.0 \\
$5 \mathrm{~nm}$ Si film & 58.1 & 3.0 \\
$10 \mathrm{~nm}$ Si film & 10.2 & 0.8
\end{tabular}

and the profile of the grains on the surface was of $1 \sim 2 \mathrm{~nm}$ height which was also similar with that of the $10 \mathrm{~nm}$ film. There was no obvious change in the surface topography of the film with more thickness and we could conclude that the deposited $10 \mathrm{~nm}$ Si film was already continuous.

Besides, the nuclei with the size of $1 \sim 2 \mathrm{~nm}$ distributed on the continuous Si film, which were even smaller than the initial crystallize nuclei, were considered as the deposition unit in deposition process. The nanoscale cluster was refined by the impact of the plasma ions and the ionized to-bedeposited $\mathrm{Si}$ atoms with high energy. The nanoscale deposition units would effectively increase the interaction between the deposited Si units and realize the densification of the film which could finally improve the macroscopic properties of the deposited film.

\section{Conclusion}

In this work, the nanoscale Si films were deposited by plasma ion assisted deposition (PIAD) on glass substrate. Our emphases were focused on the topographic signature of the $\mathrm{Si}$ 


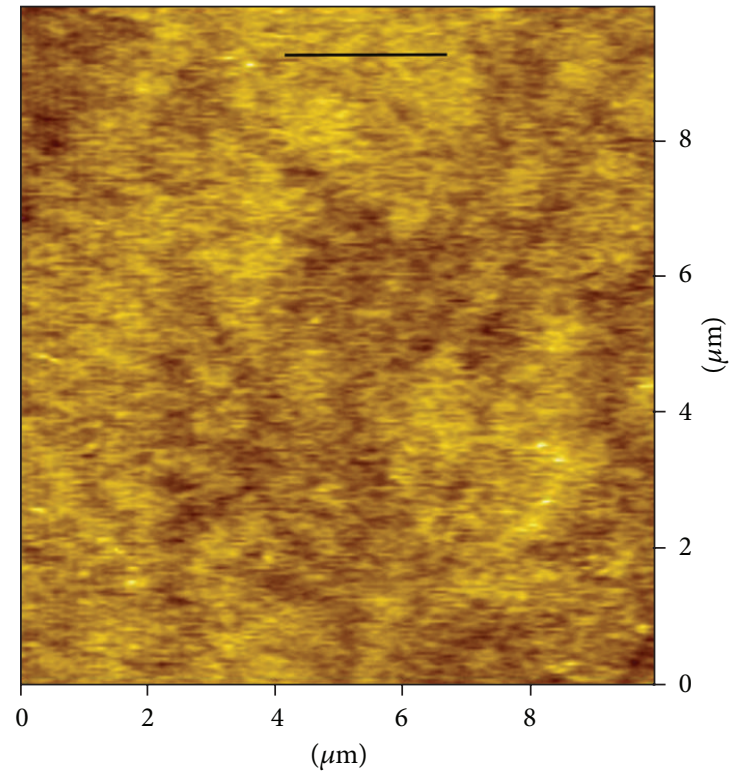

(a)

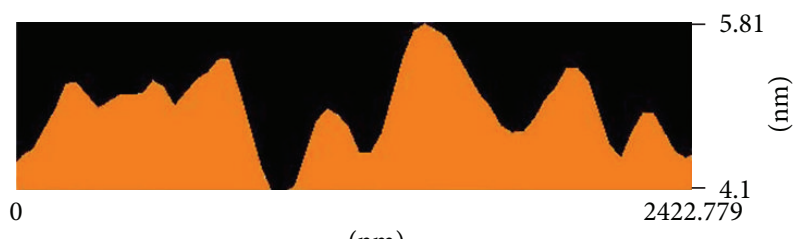

(nm)

(b)

FIGURE 5: The AFM topographic image and the line scan profile of the surface of the $20 \mathrm{~nm}$ Si deposited film.

nucleate and the growth mechanism of the film. The AFM was used to investigate the surface topography of the deposited Si film. The nucleation of the deposited Si on the substrate was observed and the spheroid nuclei were explored on the surface of the substrate at the initial stage of the film forming. As the deposition continued, the nucleus grew larger in size and the evidence of the nucleus coalescence was also shown in the line scan profile. The continuous film had been already formed when the film thickness reached $10 \mathrm{~nm}$. The growth process of Si film was found to accord with the Volmer-Weber growth mode, and the deposited Si clusters with the size of $1-2 \mathrm{~nm}$, as the deposition units, were always present on the surface of the as-deposited continuous Si film in the PAID process.

\section{Acknowledgments}

Y. Yang thanks the Century Program (One-Hundred-Talent Program) of the Chinese Academy of Sciences for special funding support, and thanks for the support by fund from Key Laboratory of Nanodevices and Applications, Suzhou Institute of Nano-Tech and Nano-Bionics, Chinese Academy of Sciences (no. 12CS01). This study was also supported in part by a fund from the National Natural Science Foundation of China (NSFC, Contract no. 51071167, 51102266), Shanghai Pujiang Program (no. 10PJ1410700), and Yangtze River Delta Science Project (11495810100).

\section{References}

[1] G. L. Liu, Z. R. Huang, J. H. Wu et al., "Surface morphology evolution and properties of silicon coating on silicon carbide ceramics by advanced plasma source ion plating," Surface and Coatings Technology, vol. 207, pp. 204-210, 2012.

[2] M. A. Ealey and J. A. Wellman, "Polishability of CERAFORM: silicon carbide," in Advanced Materials for Optical and Precision Structures, vol. 2857 of Proceedings of SPIE, pp. 78-85, 1996.

[3] L. Rich and D. A. Crowe, "Polishing process for concave lightweight silicon-coated silicon carbide optics," in Silicon Carbide Materials for Optics and Precision Structures, vol. 2543 of Proceedings of SPIE, pp. 236-247, July 1995.

[4] A. Wohllebe, R. Carius, L. Houben et al., "Crystallization of amorphous Si films for thin film solar cells," Journal of NonCrystalline Solids, vol. 227-230, no. 2, pp. 925-929, 1998.

[5] M. Li, Y. Liu, Y. Lin et al., "Study on amorphous silicon thin film by aluminum-induced crystallization," Physics Procedia, vol. 18, pp. 77-80, 2011.

[6] Y. Zhou, B. Zhou, J. Gu, M. Zhu, and F. Liu, "Comparison of growth mechanisms of silicon thin films prepared by HWCVD with PECVD," Thin Solid Films, vol. 516, no. 5, pp. 564-567, 2008.

[7] M. Grischke, K. Bewilogua, K. Trojan, and H. Dimigen, “Application-oriented modifications of deposition processes for diamond-like-carbon-based coatings," Surface and Coatings Technology, vol. 74-75, no. 2, pp. 739-745, 1995.

[8] C. K. Chung and B. H. Wu, "Effect of amorphous Si layer on the reaction of carbon and silicon in the $\mathrm{C} / \mathrm{Si}$ multilayer by high vacuum annealing," Thin Solid Films, vol. 515, no. 4, pp. 19851991, 2006.

[9] G. L. Liu, Surface finish, coating and optical properties of $\mathrm{SiC}$ materials [Ph.D. thesis], Shanghai Institute of Ceramics, CAS, 2009.

[10] W. Y. Si Lei and L. Guojun, "Deposition techniques for optical tlfin films," Journal of ChangChun University of Science and Technology, vol. 27, p. 4, 2005.

[11] P. J. Martin, H. A. Macleod, R. P. Netterfield, C. G. Pacey, and W. G. Sainty, "Ion-beam-assisted deposition of thin films," Applied Optics, vol. 22, no. 1, pp. 178-184, 1983.

[12] J. D. Targove and H. A. Macleod, "Verification of momentumtransfer as the dominant densifying mechanism in ion-assisted deposition," Applied Optics, vol. 27, pp. 3779-3781, 1988.

[13] J. Harhausen, I. Meyenburg, A. Ohl, and R. Foest, "Characterization of the plasma plume of a PIAD plasma source by means of optical emission spectroscopy," Surface and Coatings Technology, vol. 205, no. 2, pp. S407-S410, 2011.

[14] A. Zöller, R. Götzelmann, K. Matl, and D. Gushing, “Temperature-stable bandpass filters deposited with plasma ionassisted deposition," Applied Optics, vol. 35, no. 28, pp. 56095612, 1996.

[15] R. Polini, P. D’Antonio, and E. Traversa, "Diamond nucleation from the gas phase onto cold-worked Co-cemented tungsten carbide," Diamond and Related Materials, vol. 12, no. 3-7, pp. 340-345, 2003. 
[16] M. D. Whitfield, J. A. Savage, and R. B. Jackman, "Nucleation and growth of diamond films on single crystal and polycrystalline tungsten substrates," Diamond and Related Materials, vol. 9, no. 3-6, pp. 262-268, 2000.

[17] M. Balaji, A. Claudel, V. Fellmann et al., "Effects of AlN nucleation layers on the growth of AlN films using high temperature hydride vapor phase epitaxy," Journal of Alloys and Compounds, vol. 526, pp. 103-109, 2012.

[18] Y. L. Geng, D. Xu, X. Q. Wang, D. Y. Pan, G. H. Zhang, and G. W. $\mathrm{Yu}$, "Investigation of nucleation growth mechanism of MMTC crystal by AFM," Journal of Crystal Growth, vol. 280, no. 1-2, pp. 266-270, 2005.

[19] K. L. Chopra, Thin Film Phenomena, Chapter 4, McGraw-Hill, New York, NY, USA, 1969.

[20] S. K. Mishra, P. K. P. Rupa, and L. C. Pathak, "Nucleation and growth of DC magnetron sputtered titanium diboride thin films," Surface and Coatings Technology, vol. 200, no. 12-13, pp. 4078-4081, 2006. 

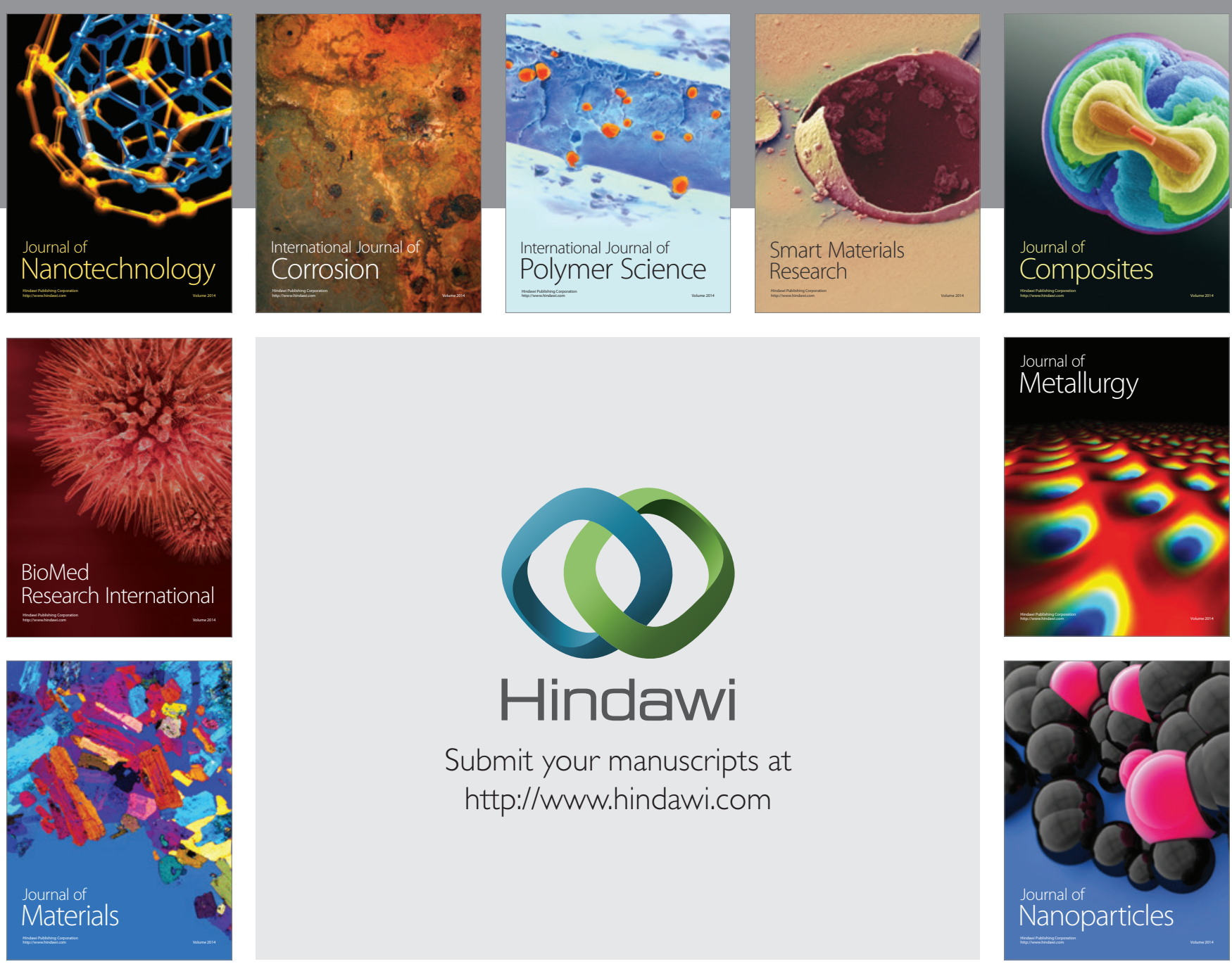

Submit your manuscripts at http://www.hindawi.com
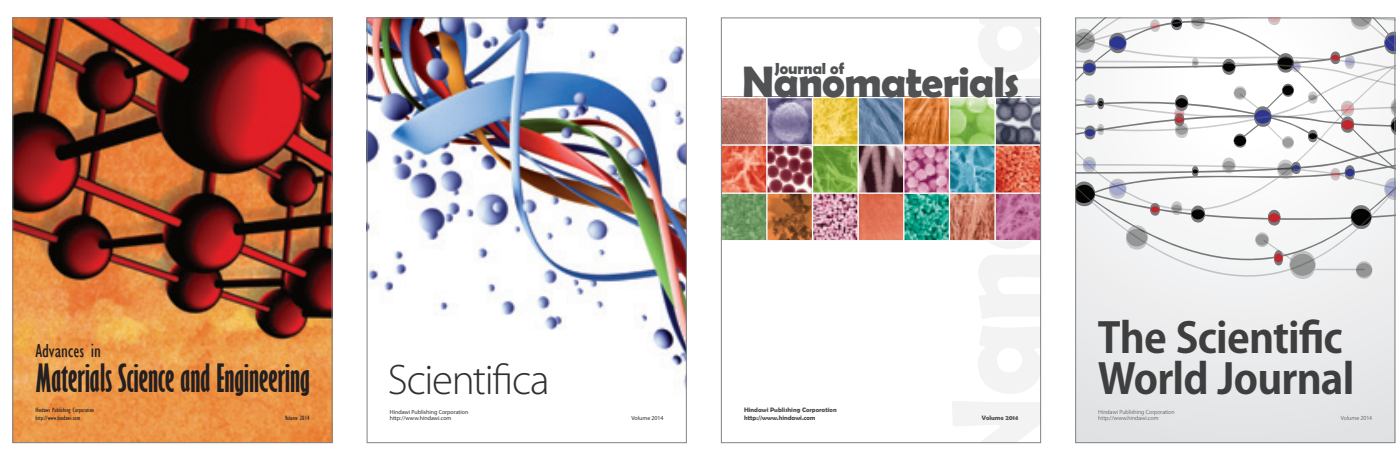

\section{The Scientific World Journal}
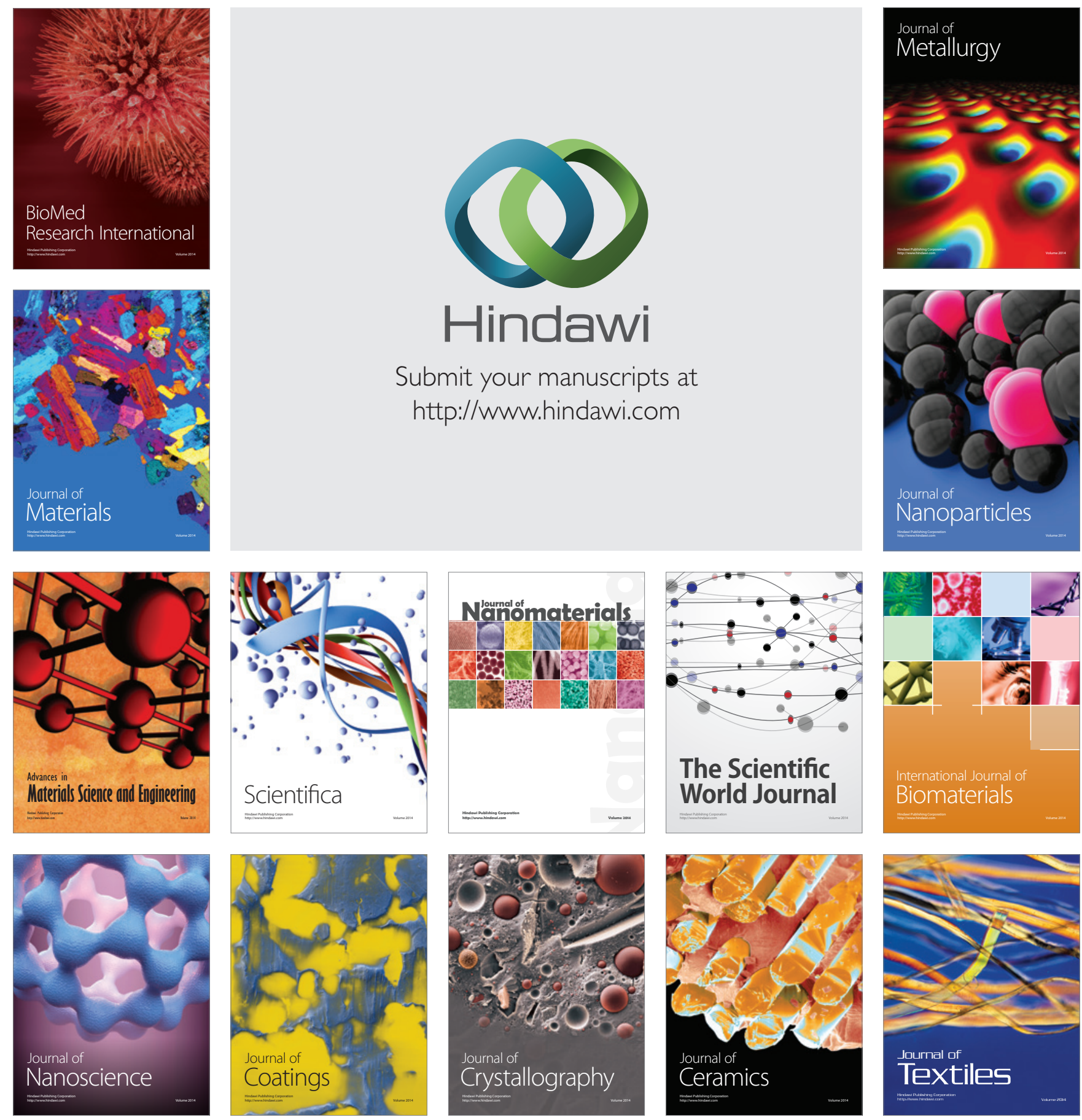